\title{
End-of-life upcycling of robust polyurethanes using a room temperature, mechanism-based degradation
}

\section{Ephraim Morado}

University of Illinois

Douglas Ivanoff

University of Illinois

Hsuan-Chin Wang

University of Illinois

Alayna Johnson

University of Illinois

Mara Paterson

University of Illinois

Darius Daniels

University of Illinois

Aoon Rizvi

University of Illinois

Nancy Sottos

University of Illinois

Steven Zimmerman ( $\square$ sczimmer@illinois.edu )

University of Illinois at Urbana-Champaign https://orcid.org/0000-0002-5333-3437

\section{Article}

Keywords: Recyclable Polymeric Materials, Life Span Properties, End of Life Degradation, Gated Chainshattering, Intramolecular Cyclization

Posted Date: May 3rd, 2021

DOI: https://doi.org/10.21203/rs.3.rs-401646/v1

License: (c) (i) This work is licensed under a Creative Commons Attribution 4.0 International License.

Read Full License 


\title{
End-of-life upcycling of robust polyurethanes using a room
}

\section{temperature, mechanism-based degradation}

\author{
Ephraim G. Morado, ${ }^{1}$ Douglas G. Ivanoff, ${ }^{2,3}$ Hsuan-Chin Wang, ${ }^{1}$ Mara L. Paterson, ${ }^{1}$ Alayna Johnson, ${ }^{1}$ \\ Darius Daniels, ${ }^{1}$ Aoon Rizvi, ${ }^{1}$ Nancy R. Sottos, ${ }^{2,3}$ and Steven C. Zimmerman ${ }^{*}, 1$ \\ 1Department of Chemistry, ${ }^{2}$ Department of Materials Science and Engineering, ${ }^{3}$ Beckman Institute for Advanced \\ Science and Technology, University of Illinois at Urbana-Champaign, Urbana, Illinois 61801, USA
}

\begin{abstract}
A major challenge in developing recyclable polymeric materials is the inherent conflict between the properties required during and after its life span. In particular, materials must be strong and durable when in use, but undergo complete and rapid degradation upon end-of-life. We report a new mechanism for degrading polyurethanes called CyclizAtion-Triggered $\mathrm{CHain}(\mathrm{CATCH})$ cleavage that achieves this duality. CATCH cleavage features a simple glycerol-based acyclic acetal unit as a kinetic and thermodynamic trap for gated chain-shattering. Thus, an organic acid induces transient chain breaks with oxocarbenium ion formation and subsequent intramolecular cyclization to depolymerize fully the polyurethane backbone at room temperature. With minimal chemical modification, the resulting degradation products can be repurposed into strong adhesives and photochromic coatings demonstrating the potential for upcycling. The $\mathrm{CATCH}$ cleavage strategy for low-energy input breakdown and subsequent upcycling may be generalizable to a broader range of synthetic polymers and their end-of-life waste streams.
\end{abstract}

The global challenge to reduce polymeric waste entering oceans and landfills has increased in urgency as the scale of problem has come into focus. ${ }^{1,2}$ Of the many approaches to make polymeric materials more sustainable, closed loop recycling have been especially interesting where depolymerization produces the original monomer. ${ }^{3,4}$ The process can be quite efficient for some materials, however others, especially thermosets require harsh conditions and most often the breakdown is insufficiently clean and too energy intensive to be practical. ${ }^{5}$ Dynamic 
covalent chemistry ${ }^{6}$ offers one promising strategy to make entirely new polymeric materials that contain chemical linkages that are easily broken. ${ }^{7,8}$ A complementary approach uses existing polymer chemistry but new degradation processes to generate either the original monomers for recycling or alternative breakdown products for upcycling applications. ${ }^{3-5}$ In this regard, a particularly challenging polymer is polyurethane.

The widespread commercial success of polyurethane is attributable to both its ease of synthesis via polyaddition polymerization of polyols and polyisocyanates and especially their superior materials properties. ${ }^{9}$ Indeed, polyurethanes are found in a wide range of consumer products from durable foams, rubbers, and adhesives to hard plastics and coatings. The high stability of the urethane linkage provides outstanding durability but makes polyurethanes particularly difficult to recycle and, thus, more likely to accumulate in oceans and landfills. Given the low reactivity of the urethane linkage, one degradation strategy is to integrate a more readily cleavable bond into either the isocyanate or polyol monomer. However, a key property of polyurethane is its hydrophobicity, making hydrolysis significantly more challenging. For example, a polyurethane containing ketal groups was reported to be resistant to hydrolysis even at $\mathrm{pH} 1$ and elevated temperature for two weeks (Fig. 1a). ${ }^{10}$ These studies underscore the central paradox of the plastic recycling problem. ${ }^{11}$ Whereas long-lived, robust properties are a requirement for the life-span of the material, a rapid and complete degradation under mild conditions is desirable for their disposal and possible recycling/upcycling. Herein we report one strategy to achieve this conflicting duality with a gated polyurethane that responds to two signals with transient breaks that are kinetically trapped leading to full breakdown. Further, we show the upcycling of the degradation products into strong adhesives and coatings.

\section{Results and Discussion}

Design of polyurethanes with gated cleavage using a CATCH mechanism. Ring-chain equilibria have proven a useful strategy for depolymerizing suitable condensation polymers. ${ }^{12}$ Clever tuning of the monomer structure can produce high molecular weight polymers with useful properties that can be repeatedly cycled between monomer and polymer. ${ }^{13}$ Our design was also influenced by stimuli responsive degradable polymers that undergo chain cleavage through iterative cyclization processes. ${ }^{14,15,16,17}$ Thus, the need for water was obviated by pendant alcohol 
groups proximal to an acetal (see 1) that undergo cyclization upon induction of transient oxocarbenium ion chain breaks (2, see Fig. 1b,c). The resulting cyclic acetal (3) serves as a kinetic and thermodynamic trap for chain cleavage in a process we refer to as CATCH cleavage. As outlined in Fig. 1d, an organic solvent might permeabilize the polyurethane allowing entry of an organic acid that would catalyze CATCH cleavage. The resultant gated

a

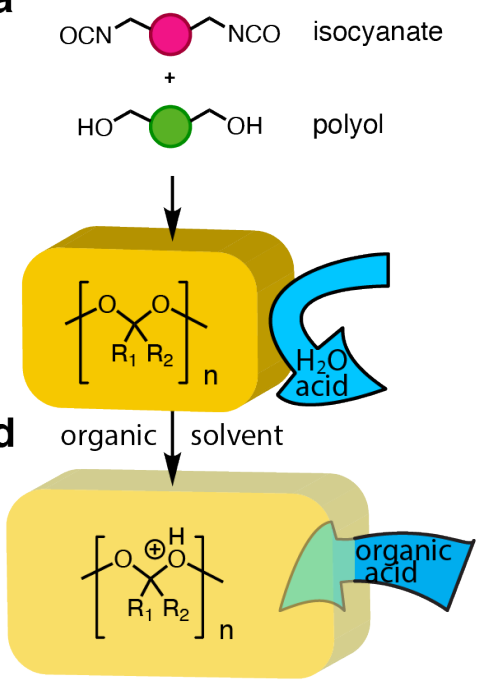

b CyclizAtion-Triggered CHain (CATCH) cleavage

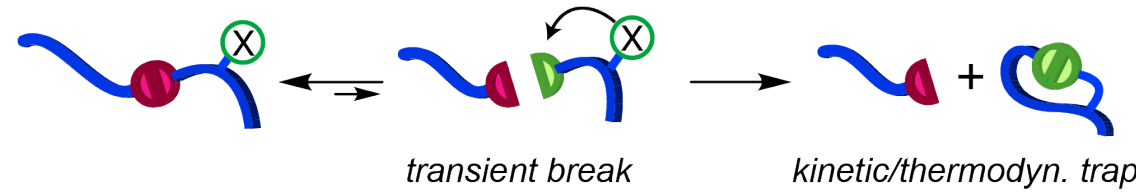

C

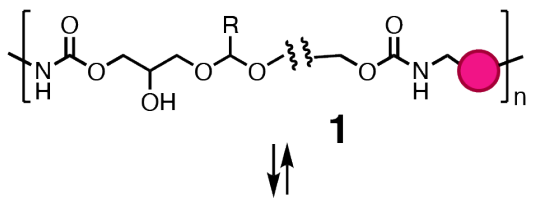<smiles>O=C(COC(O)CO)NCOCNC(=O)OCC(O)CO</smiles>

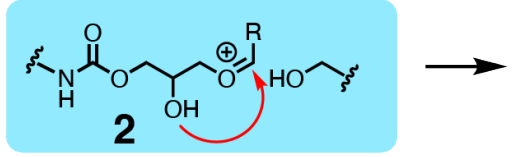

Fig. 1 | Polyurethanes and Proposed CATCH Cleavage. a, Polyaddition polymerization of polyisocyanate and an acetal or ketal-containing polyol to give polyurethane. Typical polyisocyanates produce hydrophobic polyurethanes that resist hydrolysis. b, Generalized CATCH cleavage mechanism, wherein transient chain break is trapped by pendant group in ring closing reaction. c, Acid catalyzed formation of transient oxocarbenium ion 2 (blue box) that can be trapped by pendant alcohol group giving cyclic acetal $\mathbf{3}$. Cleavage of acetal groups gives new polyol $\mathbf{4}$ corresponding to glycerol addition to polyisocyanate. $\mathbf{d}$, Organic solvent can make the bulk urethane more permeable and deliver acid for sufficient acetal degradation.

system would avoid premature breakdown. We describe here a simple acetal-containing polyol (5, Fig. 2) that crosslinks commercial diisocyanates to form robust polyurethanes $\mathbf{1}$ that are capable of undergoing this type of gated CATCH cleavage degradation to 3 with the derived polyol 4 capable of upcycling into other polyurethane materials. Thus, polyurethanes derived from $\mathbf{5}$ are robust but can be degraded with minimal energy input and given a useful second life through repurposing.

Polyol synthesis and mechanistic verification in a model. The synthesis of tetrol $\mathbf{5}$ was accomplished in two steps using a preparation that was conveniently performed on a $50 \mathrm{~g}$ scale. Thus, butyraldehyde and allyl alcohol reacted into the corresponding acetal that underwent Upjohn dihydroxylation (Fig. 2a). To test the potential for the CATCH cleavage mechanism in a model system, $\mathbf{5}$ was reacted with butylisocyanate to give $\mathbf{6}$ (Fig. 2b). A small amount of product from reaction at a secondary alcohol group was observed and this was removed during 
purification. With ${ }^{1} \mathrm{H}$ NMR monitoring, a solution of 6 with $0.5 \mathrm{~mol} \% p$-toluenesulfonic acid in anhydrous acetonitrile- $d_{3}$ was shown to transform smoothly over a $6 \mathrm{~h}$ period ( $\mathrm{t}_{1 / 2} \sim 40 \mathrm{~min}$, Supplementary Fig. 1) to at least two new species. The ${ }^{1} \mathrm{H}$ NMR and MS were fully consistent with formation of cyclic acetal $\mathbf{7}$ and diol $\mathbf{8}$, the former a mixture of diastereomers. In addition to supporting the Fig. 1c cleavage mechanism, the small molecule model demonstrated the significantly greater reactivity of the primary vs. secondary alcohol with alkyl isocyanates.

Synthesis and degradation of polyurethane elastomers. Following the successful verification of the proposed cleavage mechanism, we sought to demonstrate an analogous acetal degradation in a crosslinked polyurethane. Thus, elastomeric polyurethane film $\mathbf{1 0}$ was prepared from tetrol $\mathbf{5}$ and toluene 2,4-diisocyanate terminated poly(propylene glycol) (PPG-TDI, $M_{\mathrm{n}} \sim 2,300$ ) by mixing 5 and PPG-TDI in a 1:2 ratio (Fig. 2c,d).

Different ratios of 5 with PPG-TDI were tested with a 1:2 ratio providing the lowest amount of 5 while maintaining

a

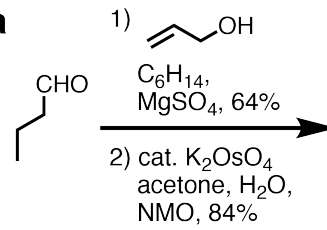

C<smiles>C=C(COC(C)(C)C(=O)OC(=O)Nc1ccc(C)c([N+](=O)[O-])c1)C(=O)Nc1ccc(C)c([N+](=O)[O-])c1</smiles>

9

d

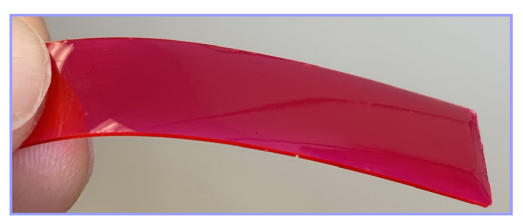

1) rhodamine $B$, cast on PTFE mold 2) cure $95^{\circ} \mathrm{C}, 12 \mathrm{~h}$

3) room temp, $12 \mathrm{~h}$

b

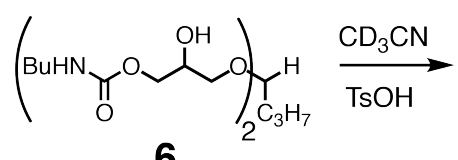

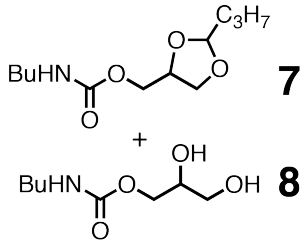

\section{8}

e

\begin{tabular}{|c|c|c|c|}
\cline { 2 - 3 } \multicolumn{1}{c|}{} & \multicolumn{2}{c|}{$T_{\mathrm{g}}\left({ }^{\circ} \mathrm{C}\right)$} & \multicolumn{1}{c}{} \\
\hline sample & DSC & DMA & $E^{\prime}(\mathrm{MPa})$ \\
\hline $10 a$ & $-45.9 \pm 0.1$ & $-40.0 \pm 0.2$ & $1.88 \pm 0.05$ \\
\hline 11 & $-49.4 \pm 0.4$ & $-41.7 \pm 1.3$ & $2.26 \pm 0.13$ \\
\hline
\end{tabular}

Fig. 2 I Preparation of acetal-containing polyurethane films. a, preparation of tetrol monomer 5. b, Model urethane acetal 6 undergoes CATCH cleavage. c, Preparation of polyurethane elastomeric films 10 and 11 using PPG-TDI (Mn $\sim 2,300$ ) and polyol 5 or 9 with rhodamine B dye for visualization. Terminal oxygen atoms signify mixture of polymer mainchain or alcohol groups and also some cross-links. d, Typical $1 \mathrm{~mm}$ thick $40 \times 5 \mathrm{~mm}$ elastomeric films prepared from 1:2 ratio of 5 to PPG-TDI with casting on a PTFE mold and curing at $95{ }^{\circ} \mathrm{C}$ for $12 \mathrm{~h}$. Scale bar, $1 \mathrm{~cm}$. e, $T_{\mathrm{g}}$ values for films $10 \mathrm{a}$ (1:2 ratio of PPG-TDI to 9), 11 measured by DSC and DMA and storage modulus $\left(E^{\prime}\right)$ at $25^{\circ} \mathrm{C}$. Values are averages of three independent runs and errors are standard deviations. 
the desired CATCH cleavage degradation. An analogous elastomeric film (11), physically indistinguishable from that shown in Fig. 2d, was prepared from tetrol 9 (Fig. 2c). Polyurethane film 11 serves as a control because 9 lacks the acetal group and therefore the ability to degrade by $\mathrm{CATCH}$ cleavage. Beyond the two films having identical physical appearances, their thermal and viscoelastic properties as measured by differential scanning calorimetry (DSC) and dynamic mechanical analysis (DMA) are similar (Fig. 2e). More importantly, thermal gravimetric analysis (TGA) of both films showed similar onset degradation temperatures $\left(>200^{\circ} \mathrm{C}\right)$, indicating their comparable thermal stability (Supplementary Fig. 2). The TGA results provide evidence that thermal degradation is not impaired by the degradable bonds of the acetal moiety. Film 10a with a 2:1 PPG-TDI to tetrol ratio was further characterized by FT-IR which showed a clear alcohol stretch at ca. $3400 \mathrm{~cm}^{-1}$ but no detectable residual isocyanate peaks. In contrast, film 10b with a 5:1 PPG-TDI to tetrol ratio showed a residual isocyanate band at ca. $2270 \mathrm{~cm}^{-1}$ but a negligible alcohol absorption consistent with nearly full reaction of all four alcohol groups. Based on the characterization and degradation data, the polyurethane elastomer prepared with a 2:1 PPG-TDI to tetrol ratio was used for further study because each acetal unit was likely to have at least one residual unreacted alcohol group to participate in $\mathrm{CATCH}$ cleavage.

To test the potential degradation of the bulk polyurethane elastomeric materials, $40 \times 10 \times 1 \mathrm{~mm}$ films $\mathbf{1 0 a}$ and 11 containing rhodamine B were immersed in a range of organic solvents containing different organic acids as well as $1 \mathrm{M}$ aqueous $\mathrm{HCl}$ (see Fig. 3 and Supplementary Figs. 3 and 4). Films of 10a immersed in THF containing $1 \mathrm{M}$ methane sulfonic acid (MSA) completely dissolved within $20 \mathrm{~min}$ at room temperature (Supplementary Movie 1) but showed no visible change with immersion in a $1 \mathrm{M}$ aqueous $\mathrm{HCl}$ solution for $2 \mathrm{~d}$. The striking difference in the rate of disappearance of polyurethane elastomer $\mathbf{1 0}$ supports the notion of rapid degradation in low moisture environments via the CATCH cleavage mechanism and further highlights the stability of hydrophobic acetalcontaining polyurethanes in strongly acidic aqueous environments. In contrast, the acetal-free film $\mathbf{1 1}$ experienced swelling and some dye loss but otherwise remained fully intact upon immersion in THF with 1 M MSA.

We performed tensile DMA studies to test the thermomechanical response of 10a and $\mathbf{1 1}$ to gain more insight about their relative stability in aqueous acid. Films 10a and $\mathbf{1 1}$ were soaked in $1 \mathrm{M} \mathrm{HCl}$ for $24 \mathrm{~h}$ and compared to their pristine counterparts. We observed that DMA studies on 11 indicated direct overlap of the tan $\delta$ and E' curves 
a

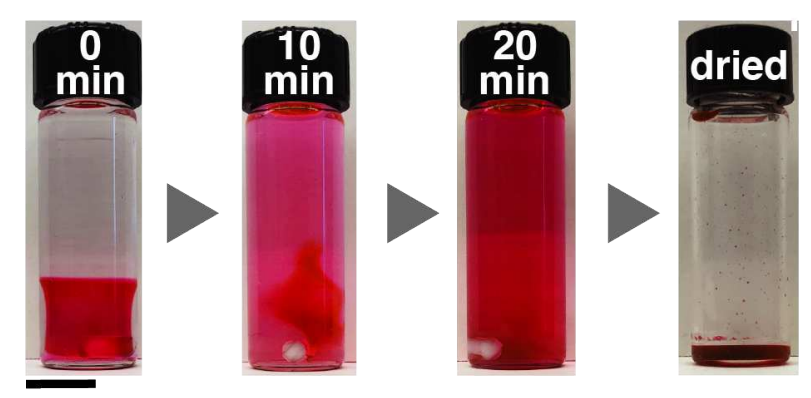

b

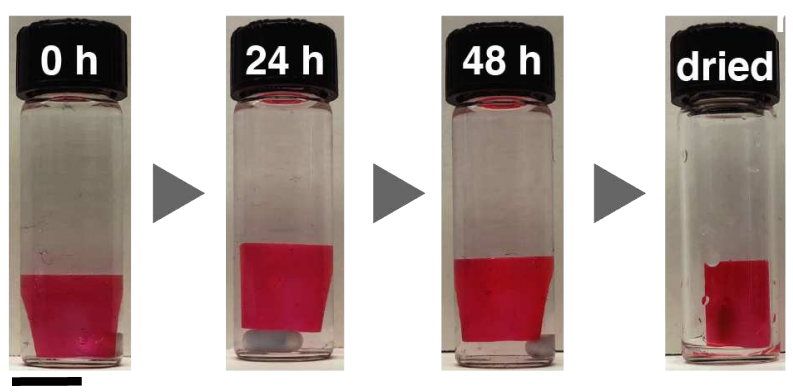

Fig. 3 | Polyurethane film degradation. a, Dissolution of polyurethane film 10a in 1M methane sulfonic acid (MSA) in THF followed by removal of solvent. Scale bar, $1 \mathrm{~cm}$. b. Same treatment of polyurethane film 11 leaves the material intact. Scale bar, $1 \mathrm{~cm}$.

for the pristine and soaked films (Fig. 4a). Although 10a has a slight shift in $E^{\prime}$ and $\tan \delta$ after soaking in $1 \mathrm{M} \mathrm{HCl}$, the rubbery plateau for the soaked films indicates that the bulk material remained crosslinked providing evidence that bulk polymer degradation is limited under aqueous acidic condition (Fig. 4b). Additional studies must be performed to determine the cause of these shifts in $\tan \delta$ and storage modulus but from a practical point of view, such durability in aqueous acid suggests that polyurethane materials derived from tetrol $\mathbf{5}$ perform well under realworld conditions. To further quantify the degradation and relative stability of these crosslinked polyurethane materials, we performed in situ storge modulus measurements while the films were immersed in a 1 M MSA in THF solution. We observed a rapid decrease of $E^{\prime}$ of $\mathbf{1 0 a}$ after addition of $1 \mathrm{M}$ MSA in THF at $100 \mathrm{~s}$, indicating rapid degradation of the film, whereas the $E^{\prime}$ of $\mathbf{1 1}$ remained unchanged providing further evidence that films without acetal groups were stable in THF/MSA solutions (Fig. 4c). 
a

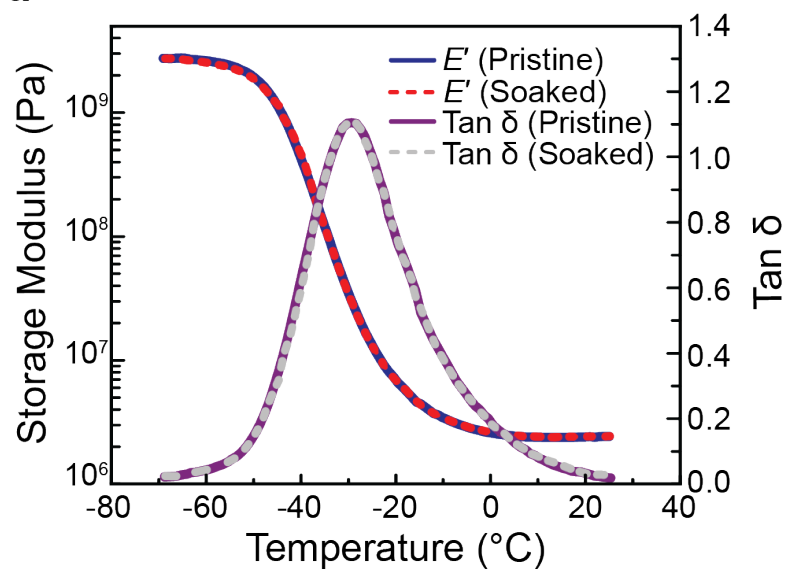

b

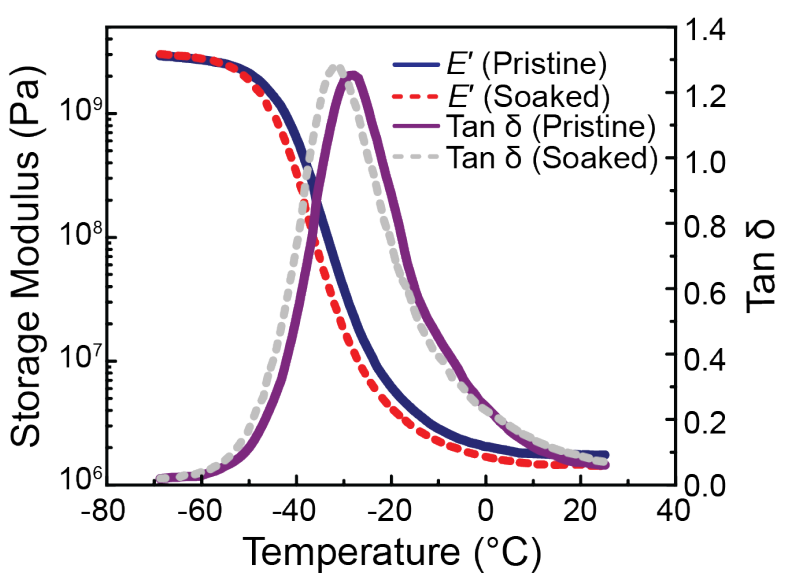

C

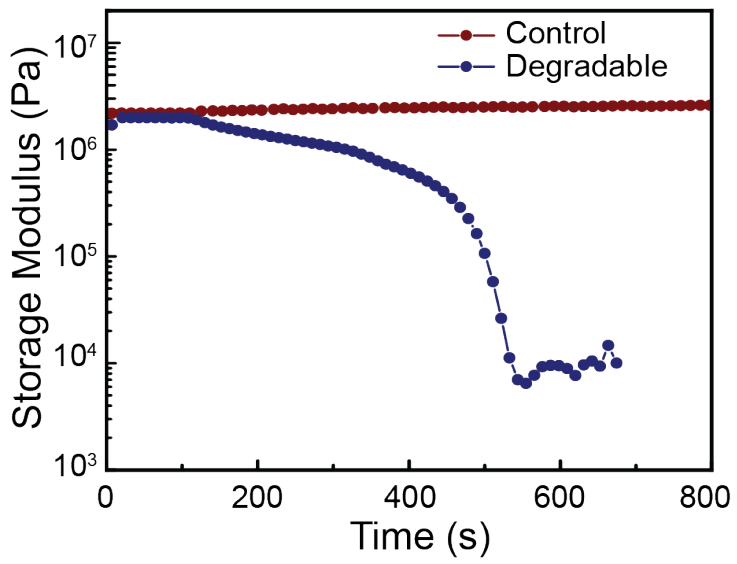

Figure 4 | Degradation study of polyurethane elastomer. a, Representative thermomechanical response of 11 films before and after soaking in $1 \mathrm{M} \mathrm{HCl}$ aqueous solution for $24 \mathrm{~h}$ showing $E^{\prime}$ and tan $\delta$ from tensile DMA. b. Representative thermomechanical response of 10a films before and after soaking in $1 \mathrm{M} \mathrm{HCl}$ aqueous solution for $24 \mathrm{~h}$ showing $E^{\prime}$ and $\tan \delta$ from tensile DMA. c, Storage modulus of 10a films (blue) and control 11 films (red) immersed in 1M MSA in THF versus time from tensile DMA.

The DMA results indicate degradation for acetal-containing polyurethane 10a whereas 11 maintains its integrity. Indirect support for the importance of the hydroxyl groups in the breakdown of polyurethane 10a comes from studies of $\mathbf{1 0 b}$ prepared with a 5:1 PPG-TDI to tetrol ratio. Analogous to 11, these elastomeric films minimally changed with the THF/MSA treatment, at least in part because nearly all the hydroxyl groups were converted to urethane linkages and thus not able to participate in $\mathrm{CATCH}$ cleavage. More direct support for the Fig. 1c mechanism was provided by NMR. Thus, the HSQC spectrum of the degradation mixture showed a correlation between large and small ${ }^{1} \mathrm{H}$ resonances at $\delta 4.8 \mathrm{ppm}$ and ${ }^{13} \mathrm{C}$ signals at $104 \mathrm{ppm}$, consistent with the acetal protons and carbon of 1,3-dioxolane (major) and 1,3-dioxane (minor) units of 12 (Fig. 5a and Supplementary Fig. 5). Importantly, this signal disappeared upon hydrolysis with aqueous $\mathrm{HCl}$ to give $\mathbf{1 3}$. The extent and nature of the 
degradation was examined by MALDI-TOF MS and GPC on 12 to 13. To better grasp how the degraded material compared to the starting material, we reacted PPG-TDI with two equivalents of hexylamine to give $\mathbf{1 4}$ (Fig. 5 b) as a control. MALDI-TOF MS data indicated $\mathrm{m} / \mathrm{z}$ values for the main mass series seen in Supplementary Fig. 6 are consistent with structure 13 where n 35-45 PPG units, the same mass series present in 14 (Supplementary Fig. 6a). One other higher mass series is observed for $\mathbf{1 3}$ that corresponds to two PPG-TDI segments tethered together by a glycerol unit. The origin of this degradation product can be traced to the reaction of two PPG TDI units with a single 1,2-diol unit of 5 during the polymerization. This higher mass series is derived from the cross-linking that occurs during curing and is not seen in hexylamine-capped PPG-TDI control (Supplementary Fig. 6b). The GPC provided $Ð=2.31$ and $M_{\mathrm{n}}=7.7 \mathrm{kDa}$ for 13 and $Ð=1.93$ and $M_{\mathrm{n}}=2.85 \mathrm{kDa}$ for $\mathbf{1 4}$ (Supplementary Fig. 6c). The GPC data further support complete degradation with generation of the original PPG-TDI length and a smaller amount of higher molecular weight material derived from cross-linking. We predict that this product distribution should not affect the upcycling into new materials.

Repurposing polyurethane elastomer into strong adhesives and photochromic coatings. In addition to their utility as elastomers, polyurethanes are frequently applied as coatings, adhesives, and sealants. Indeed, they are strong and desirable adhesives with an ability to adhere to various substrates, water-repellant, and as thermosets, they have a wide range of operating temperatures. ${ }^{18,19}$ Whereas facile degradation of crosslinked polyurethane materials into processable components is an important first step towards a sustainable polyurethane lifecycle, the utility of the post-degradation materials for reuse or recycling is equally crucial.

To demonstrate the reusability of the degraded materials generated from 10a via CATCH cleavage, we chose to re-formulate the post-degradation polyol urethane prepolymer, 13, as an adhesive. Polyol $\mathbf{1 3}$ was polymerized with $15 \mathrm{wt} \%$ of industrially relevant poly[(phenylisocyanate)-co-formaldehyde] $\left(M_{\mathrm{n}} \sim 340\right)$, PAPI 2027 (15, Fig. 5c). Adhesives fabricated with PAPI 2027 exhibited strong adhesion to both aluminum and glass substrates. The adhesives withstood a $20 \mathrm{lb}$ weight for $24 \mathrm{~h}$ and $3 \mathrm{~h}$ for glass and aluminum, respectively (Fig. 5c). The significantly stronger adhesion to glass likely arises from the hydrogen bonding between the polyurethane adhesive and the hydroxylated silicate surface. ${ }^{20}$ Additionally, lap shear tests were carried out on the PAPI-based adhesive for both 
a

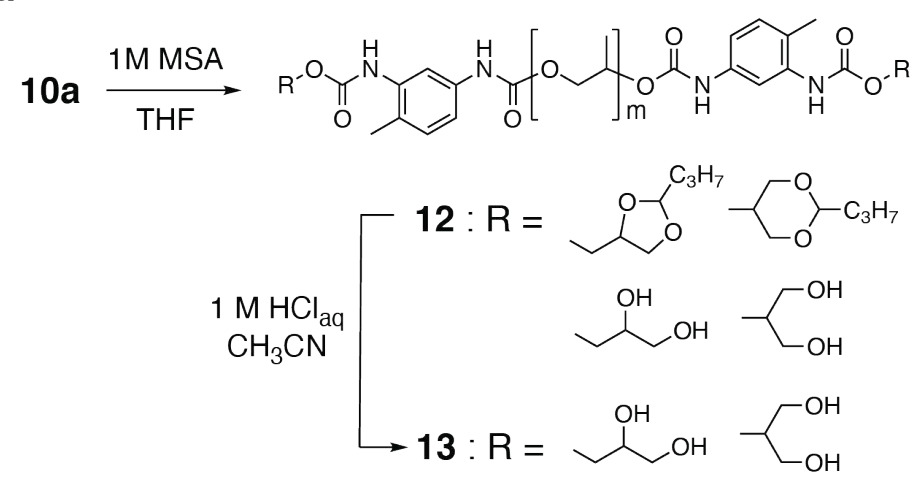

b

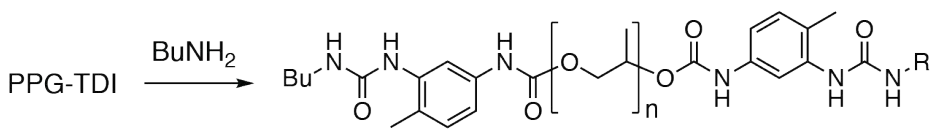

14

d

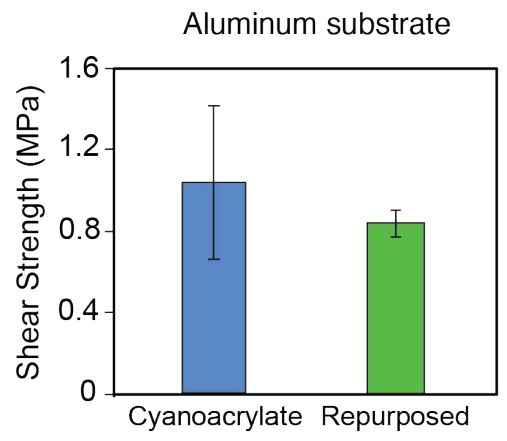

C

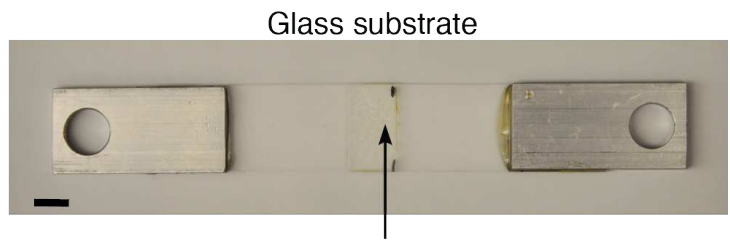

$13+$
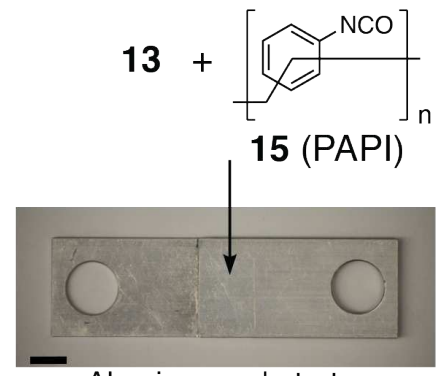

Aluminum substrate
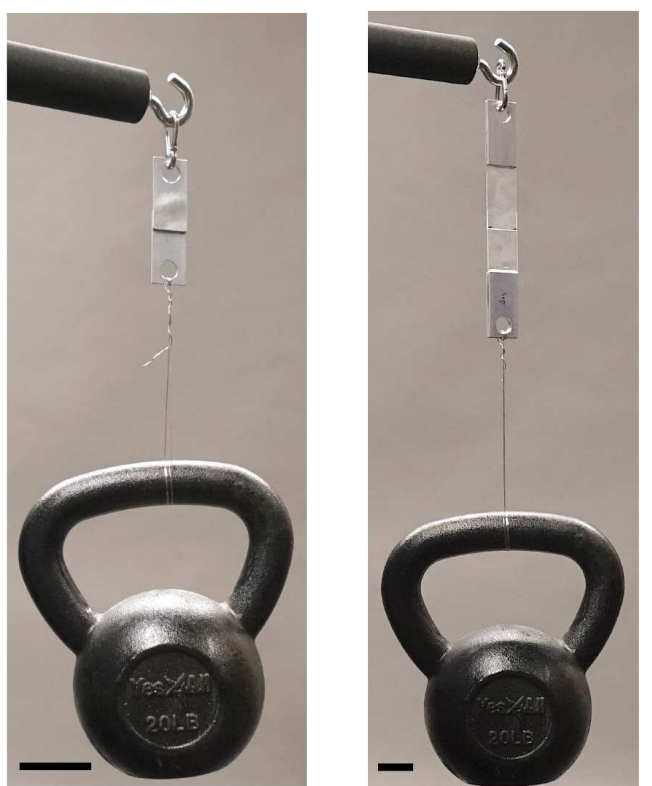

Figure 5 | Repurposing of polyurethane elastomers to strong adhesives. a, Scheme showing possible degradation products from film 10a. b. Preparation of urea 14 as a size standard for MALDI-TOF MS and GPC. c, Fabrication of PAPIbased polyurethane adhesive for steel and glass substrate. Scale bar, $1 \mathrm{~cm}$. A $20 \mathrm{lb}$ kettlebell supported by adhesive on glass substrate and steel substrate. Scale bar, $5 \mathrm{~cm}$. d, Lap shear of repurposed adhesive on steel substrate and comparison with cyanoacrylate. Average of three independent runs with error bars representing standard error of the mean. e, Lap shear results using repurposed adhesive on glass showing shattering the glass with lap-joint intact. Scale bar, $1 \mathrm{~cm}$.

substrates. Our repurposed polyurethane adhesive showed comparable magnitude of shear strength on the aluminum substrate as super glue (Figure 5d). For the glass substrate, adhesion of cyanoacrylate glue (super glue) was measured to have a shear strength of $0.8 \pm 0.3 \mathrm{MPa}$, but no measurement was obtainable with the available instrument for the repurposed polyurethane adhesive because the glass substrates fractured before any failure in the adhesive could be observed (Fig. 5e). That is, the adhesion was sufficiently strong that the glass substrate would 
break during the lap shear test. Thus, we were able to degrade and repurpose our polyurethane material into a practical product that demonstrates competitive performance and potential commercial value.

In addition to forming adhesives, polyol prepolymer $\mathbf{1 3}$ can also be repurposed for use in functional coatings. ${ }^{18,21}$ Polyurethane coatings are ubiquitous, and their properties can vary depending on the desired application but are often hard, chemically resistant, and provide appealing high-gloss finishes. As a proof of concept, we focused on demonstrating the utility and versatility of the polyol prepolymer $\mathbf{1 3}$ to formulate a photochromic coating as a light responsive coating, loosely analogous to smart window coatings. Thus, we blended a neat mixture of 13, 2,4,6-trioxotriazine-1,3,5(2H,4H,6H)tris(hexamethylene)isocyanate (16), and the well-studied spiropyran dye $\mathrm{e}^{22} \mathbf{1 7}$ to generate a UV-responsive coating material. This mixture was applied onto a glass slide using

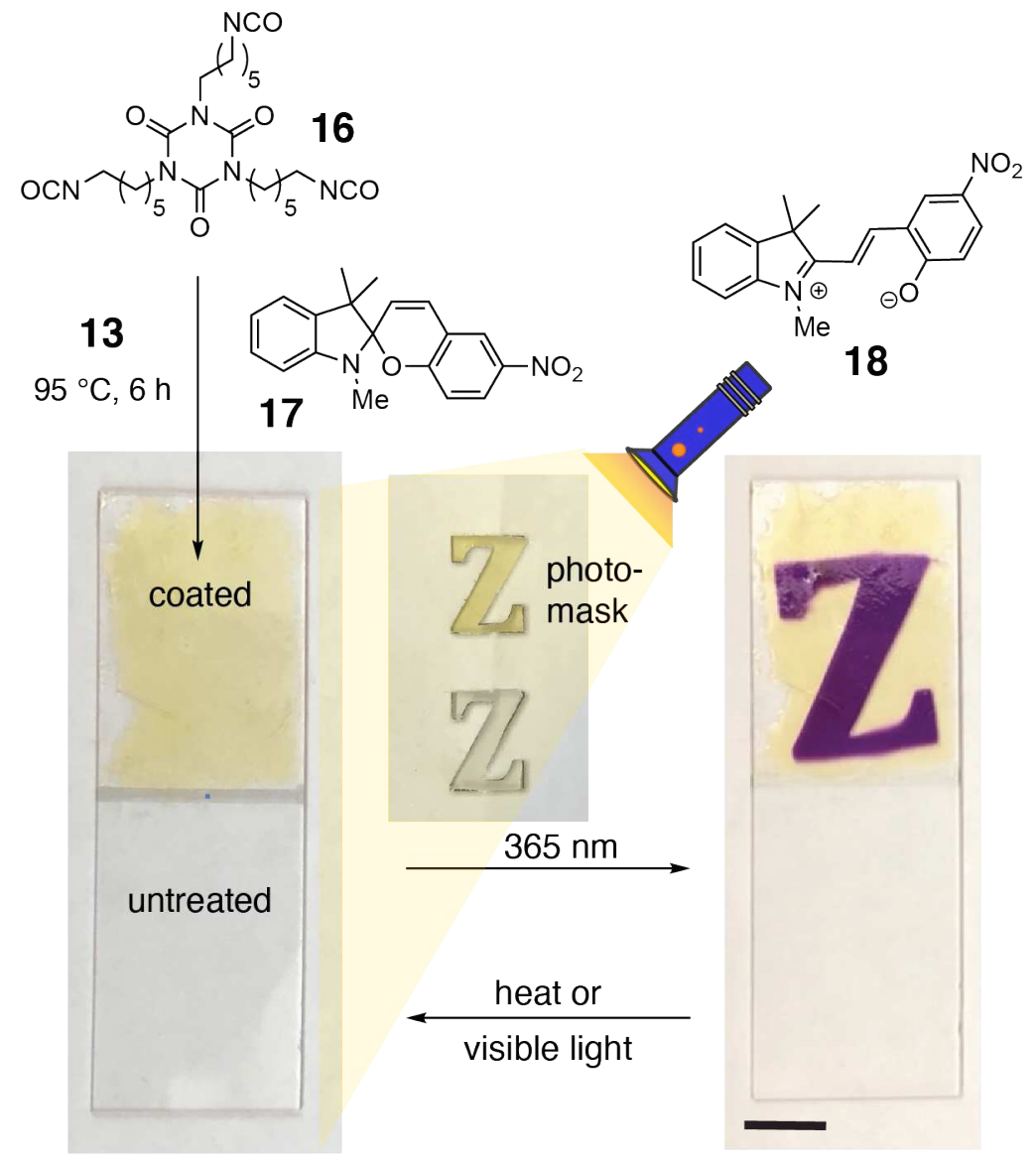

Figure 6 | Repurposing of polyurethane elastomers for photochromic coating. Fabrication of photochromic polyurethane coating on glass slide with coated (top) and untreated (bottom) halves. Photo switchable mechanism of spiropyran dye. c, Photochromic ability of coating demonstrated via 3 min irradiation with 365 nm longwave hand-held UV light and subsequent exposure to white light (ambient fluorescent laboratory lights) for 30 min reverting back to normal. Scale bar, $1 \mathrm{~cm}$. 
a paintbrush and cured (Fig. 4a). The photochromic activity of the repurposed polyurethane coating was tested by incorporating a Z-shaped mask on top of the coating and irradiated with $365 \mathrm{~nm}$ for $3 \mathrm{~min}$ which generated a purple $\mathrm{Z}$ on the coated section of the glass slide corresponding to formation of the merocyanine dye 18 . The $\mathrm{Z}$ entirely disappeared in 30 min when exposed to white light. The process was repeated for four cycles (Fig. 6, Supplementary Movie 2).

We have demonstrated that simple polyol monomer 5 forms thermally and aqueous stable polyurethane elastomeric films that can be degraded into new polyols that can be reused to make different polyurethane materials. From a sustainability standpoint, one disadvantage of $\mathbf{5}$ is its preparation utilizes the toxic osmium tetroxide for dihydroxylation. To test the generality of the $\mathrm{CATCH}$ cleavage mechanism and provide a greener alternative to $\mathbf{5}$ we prepared a new tetrol acetal from trimethylolethane as starting material. The new acetal-containing polyol monomer was conveniently prepared in three steps (Supplementary Fig. 7). Despite the alcohol groups all being primary and the $\mathrm{CATCH}$ cleavage mechanism exclusively forming six membered 1,3-dioxane rings, model polyurethane elastomeric films still degraded within 20 min under anhydrous acidic conditions and the TGA exhibited a similar onset degradation temperature $\left(280^{\circ} \mathrm{C}\right)$ to $\mathbf{1 0 a}$.

\section{Conclusions}

Because bulk polyurethane waste is made up of highly durable thermosets, it is usually incinerated or simply discarded in the environment. With the demand for polyurethane growing unabated, the safe and economically viable management of polyurethane waste will remain a key challenge facing modern society. We developed a new approach to this challenge by designing an acetal-containing polyol that is compatible with the current industrially relevant isocyanate-polyol polyurethane chemistry. The water resistant, crosslinked hydroxyacetal polyurethane demonstrated rapid acid-catalyzed depolymerization in various organic solvents at room temperature, whereas the acetal-free control polyurethane and the hydroxyl-free acetal polyurethane analog were largely unaffected by the same treatment. Additionally, the recovered polyol from the degraded waste product was successfully repurposed in two practical applications: a polyurethane adhesive with comparable performance to super glue and a photochromic coating. Again, both processes employed commercially available, industrial polyisocyanates as co- 
reagents. The generality of hydroxyacetal approach and compatibility with existing polyurethane technologies suggests its application to other polyurethane systems that include isocyanate-free polyurethane chemistries, ${ }^{23,24}$ and thereby opening a practical pathway to a new generation of sustainable polyurethanes. More broadly, the CATCH cleavage strategy should be applicable to other polymer chain functionality allowing selective and facile breakdown of other polymeric materials.

\section{Supplementary Information}

Supplementary figures as well as detailed experimental procedures, NMR spectra, additional characterization data, model studies, kinetic data, material characterization, and fabrication and degradation studies of polyurethane materials.

\section{Data Availability}

The data supporting the findings in this study are available within the article and the supplementary information.

\section{Acknowledgements}

S.C.Z. acknowledges support from the National Science Foundation (NSF CHE-1709718). N.R.S acknowledges support from the National Science Foundation LEAP HI program (NSF CMMI 1933932).

\section{Author contributions}

E.G.M, H-C.W, and S.C.Z conceived the idea. E.G.M., M.P., H-C.W. designed and synthesized the monomers and small molecule models. D.D., A.J., and A.R. assisted with the chemical synthesis. E.G.M fabricated the polyurethane materials, degradation characterization, and mechanical testing of elastomers, adhesives, and coatings. D.G.I. performed DMA and DSC studies of polyurethane elastomers and D.G.I. and N.R.S. analyzed data. E.G.M, H-C.W., and S.C.Z. prepared the manuscript.

\section{Competing interests}

The University of Illinois has filed a patent application on degradable polymers and monomers based on the hydroxyacetal chemistry described herein (US Application No. 17/217,512; inventors E.G.M., H.W., and S.C.Z.). 


\section{References}

1. Geyer, R., Jambeck, J. R. \& Law, K. L. Production, use, and fate of all plastics ever made. Sci. Adv. 3, e1700782 (2017).

2. Gibb, B. C. Plastics are forever. Nat. Chem. 11, 394-395 (2019).

3. Hong, M. \& Chen, E. Y. X. Chemically recyclable polymers: a circular economy approach to sustainability. Green Chem. 19, 3692-3706 (2017).

4. Rahimi A, Garcia J. M. Chemical recycling of waste plastics for new materials production. Nat. Rev. Chem. 1, 1-11 (2017).

5. Fortman D. J., et al. Approaches to sustainable and continually recyclable cross-linked polymers. ACS Sustain Chem. Eng. 6, 11145-11159 (2018).

6. Rowan, S. J., Cantrill, S. J., Cousins, G. R. L., Sanders, J. K. M. \& Stoddart, J. F. Dynamic covalent chemistry. Angew. Chem. Int. Edit. 41, 898-952, (2002).

7. Garcia, J. M. et al. Recyclable, strong thermosets and organogels via paraformaldehyde condensation with diamines. Science 344, 732-735 (2014).

8. Christensen, P. R., Scheuermann, A. M., Loeffler, K. E. \& Helms, B. A. Closed-loop recycling of plastics enabled by dynamic covalent diketoenamine bonds. Nat. Chem. 11, $442-448$ (2019).

9. Engels, H. W. et al. Polyurethanes: versatile materials and sustainable problem solvers for today's challenges. Angew. Chem. Int. Edit. 52, 9422-9441 (2013).

10. Lingier, S., Spiesschaert, Y., Dhanis, B., De Wildeman, S. \& Du Prez, F. E. Rigid polyurethanes, polyesters, and polycarbonates from renewable ketal monomers. Macromolecules 50, 5346-5352 (2017).

11. Sardon, H. \& Dove, A. P. Plastics recycling with a difference. Science 360, 380-381 (2018).

12. Hodge, P. Recycling of condensation polymers via ring-chain equilibria. Polym. Advan. Technol. 26, 797-803 (2015).

13. Zhu, J. B., Watson, E. M., Tang, J. \& Chen, E. Y. X. A synthetic polymer system with repeatable chemical recyclability. Science 360, 398-403 (2018).

14. Dewit, M. A. \& Gillies, E. R. A cascade biodegradable polymer based on alternating cyclization and elimination reactions. J. Am. Chem. Soc. 131, 18327-18334 (2009).

15. Olejniczak, J., Chan, M. \& Almutairi, A. Light-triggered intramolecular cyclization in poly(lactic-co-glycolic acid)-based polymers for controlled degradation. Macromolecules 48, 3166-3172 (2015).

16. Lv, A., Cui, Y., Du, F. S. \& Li, Z. C. Thermally degradable polyesters with tunable degradation temperatures via postpolymerization modification and intramolecular cyclization. Macromolecules 49, 8449-8458 (2016).

17. McKinlay, C. J. et al. Charge-altering releasable transporters (CARTs) for the delivery and release of mRNA in living animals. Proc. Natl. Acad. Sci. U.S.A. 114, E448-E456 (2017).

18. Sonnenschein, M. F. POLYURETHANES Science, Technology, Markets, and Trends. Wiley Ser. Polym. Eng. Chpt 10 (2015).

19. Segura, D. M., Nurse, A. D., McCourt, A., Phelps, R. \& Segura, A. Chemistry of polyurethane adhesives and sealants. Handbook Adhesives and Sealants 1, 101-162 (2005).

20. Cornille, A. et al. Promising mechanical and adhesive properties of isocyanate-free poly(hydroxyurethane). Eur. Polym. J. 84, 404-420 (2016). 
21. Chattopadhyay, D. K. \& Raju, K. V. S. N. Structural engineering of polyurethane coatings for high performance applications. Prog. Polym. Sci. 32, 352-418 (2007).

22. Kortekaas, L. \& Browne, W. R. The evolution of spiropyran: fundamentals and progress of an extraordinarily versatile photochrome. Chem. Soc. Rev. 48, 3406-3424 (2019).

23. Maisonneuve, L., Lamarzelle, O., Rix, E., Grau, E. \& Cramail, H. Isocyanate-free routes to polyurethanes and poly(hydroxy urethane)s. Chem. Rev. 115, 12407-12439 (2015).

24. Carre, C., Ecochard, Y., Caillol, S. \& Averous, L. From the synthesis of biobased cyclic carbonate to polyhydroxyurethanes: a promising route towards renewable non-isocyanate polyurethanes. ChemSusChem 12, 3410-3430 (2019). 


\section{Figures}

a
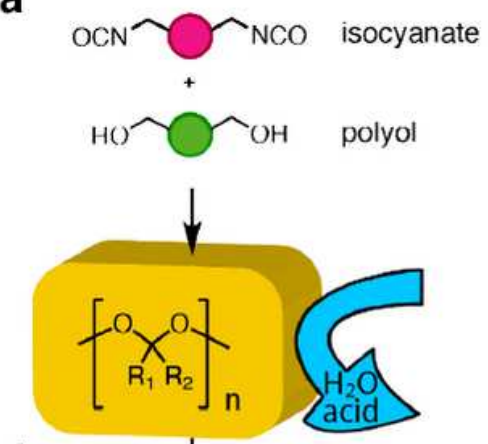

d organic $\$ solvent

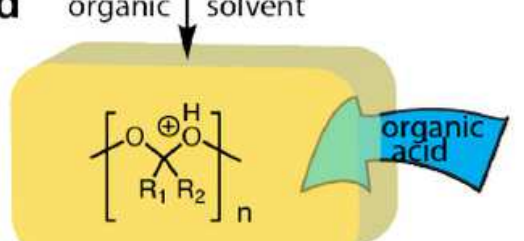

b CyclizAtion-Triggered CHain (CATCH) cleavage

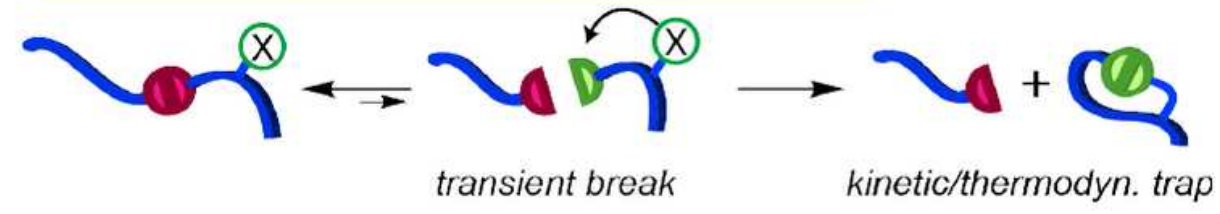

C

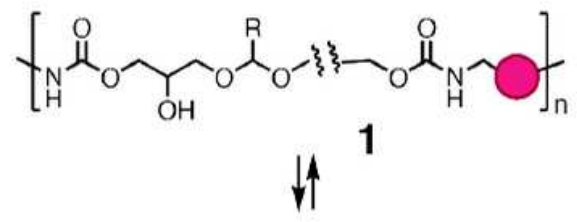<smiles>O=C(COC(=O)NCCOCC(O)CO)OCC(O)CO</smiles>

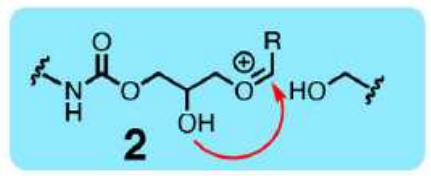<smiles>O=C(COC(=O)NCC1CCC(CC(O)CO)CC1)OCC(O)CO</smiles>

\section{Figure 1}

Polyurethanes and Proposed CATCH Cleavage. a, Polyaddition polymerization of polyisocyanate and an acetal or ketal-containing polyol to give polyurethane. Typical polyisocyanates produce hydrophobic polyurethanes that resist hydrolysis. b, Generalized CATCH cleavage mechanism, wherein transient chain break is trapped by pendant group in ring closing reaction. c, Acid catalyzed formation of transient oxocarbenium ion 2 (blue box) that can be trapped by pendant alcohol group giving cyclic acetal 3 . Cleavage of acetal groups gives new polyol 4 corresponding to glycerol addition to polyisocyanate. $d$, Organic solvent can make the bulk urethane more permeable and deliver acid for sufficient acetal degradation. 
a

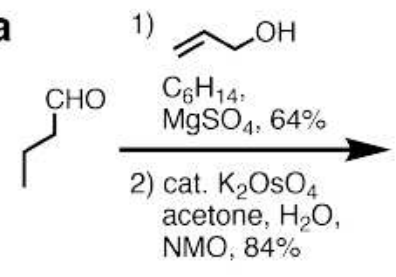

C<smiles>C=C(COC(C)(C)C(=O)Nc1ccc(C)c([N+](=O)[O-])c1)C(=O)OC(=O)Nc1ccc(C)c([N+](=O)[O-])c1</smiles>

9

d

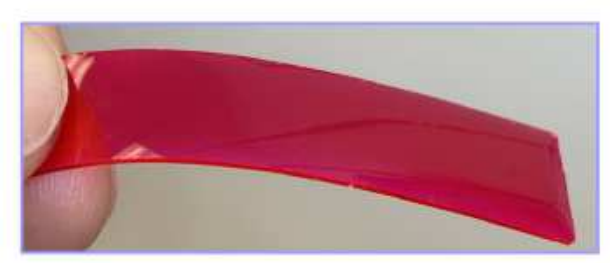

b

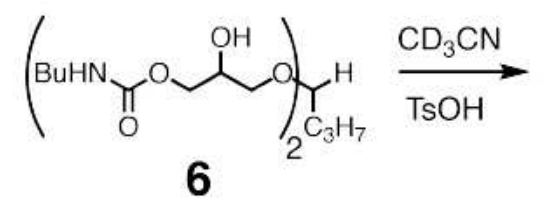

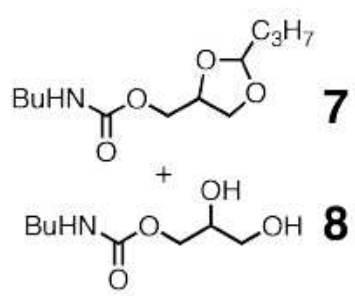

1) rhodamine $B$, cast on PTFE mold 2) cure $95^{\circ} \mathrm{C}, 12 \mathrm{~h}$

3) room temp, $12 \mathrm{~h}$<smiles>C#CC1CCC(CO)CC1OCCOCCOCC(O)CO</smiles>

10

e

\begin{tabular}{|c|c|c|c|}
\cline { 2 - 3 } \multicolumn{1}{c|}{} & \multicolumn{2}{c|}{$T_{\mathrm{g}}\left({ }^{\circ} \mathrm{C}\right)$} & \multicolumn{1}{c}{} \\
\hline sample & DSC & DMA & $E^{\prime}(\mathrm{MPa})$ \\
\hline 10a & $-45.9 \pm 0.1$ & $-40.0 \pm 0.2$ & $1.88 \pm 0.05$ \\
\hline 11 & $-49.4 \pm 0.4$ & $-41.7 \pm 1.3$ & $2.26 \pm 0.13$ \\
\hline
\end{tabular}

\section{Figure 2}

Preparation of acetal-containing polyurethane films. a, preparation of tetrol monomer 5 . b, Model urethane acetal 6 undergoes CATCH cleavage. c, Preparation of polyurethane elastomeric films 10 and 11 using PPG-TDI (Mn $\varangle 2,300)$ and polyol 5 or 9 with rhodamine B dye for visualization. Terminal oxygen atoms signify mixture of polymer mainchain or alcohol groups and also some cross-links. d, Typical 1 $\mathrm{mm}$ thick $40 \times 5 \mathrm{~mm}$ elastomeric films prepared from 1:2 ratio of 5 to PPG-TDI with casting on a PTFE mold and curing at $95^{\circ} \mathrm{C}$ for $12 \mathrm{~h}$. Scale bar, $1 \mathrm{~cm}$. e, Tg values for films 10a (1:2 ratio of PPG-TDI to 9), 11 measured by DSC and DMA and storage modulus $\left(\mathrm{E}^{\prime}\right)$ at $25^{\circ} \mathrm{C}$. Values are averages of three independent runs and errors are standard deviations. 


\section{a}

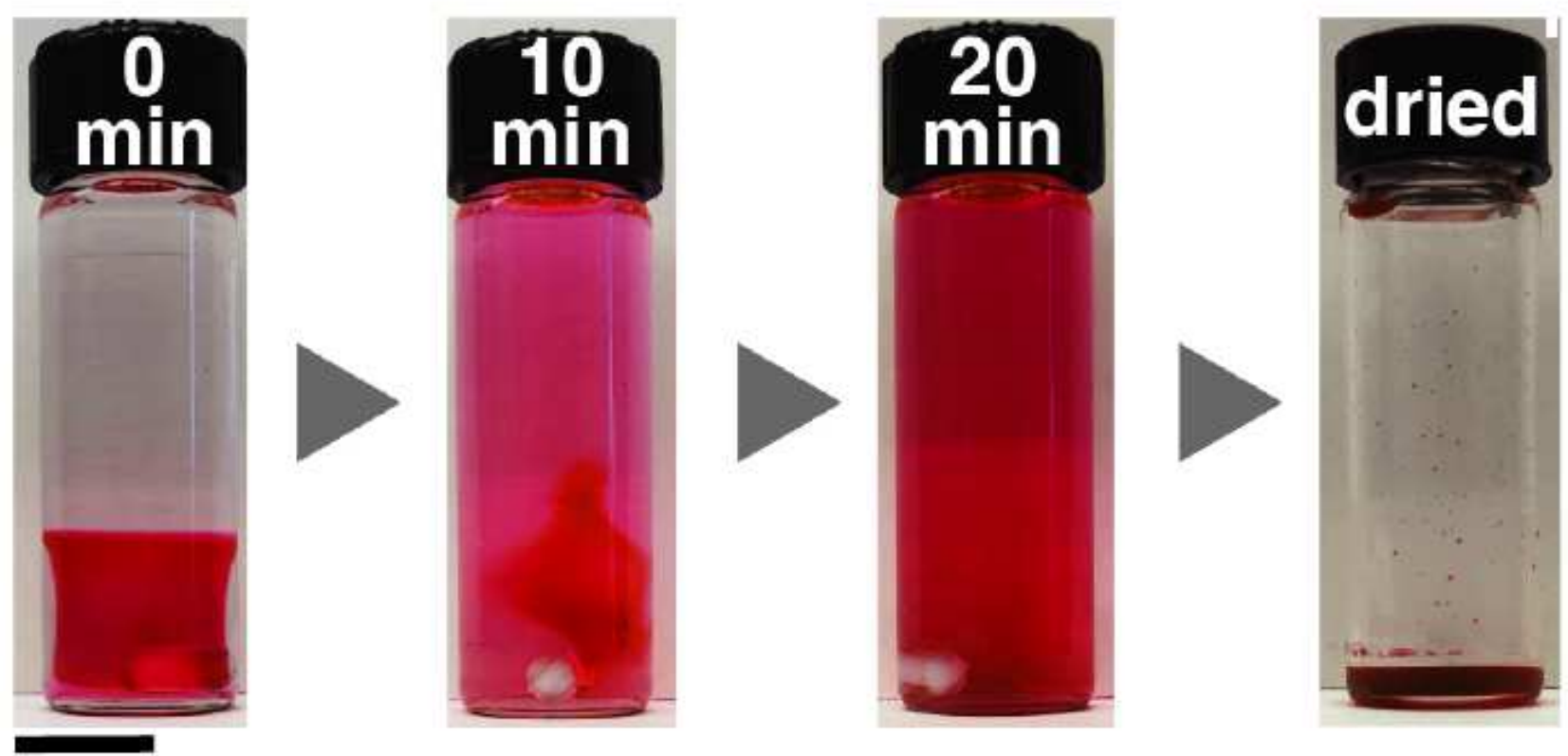

b
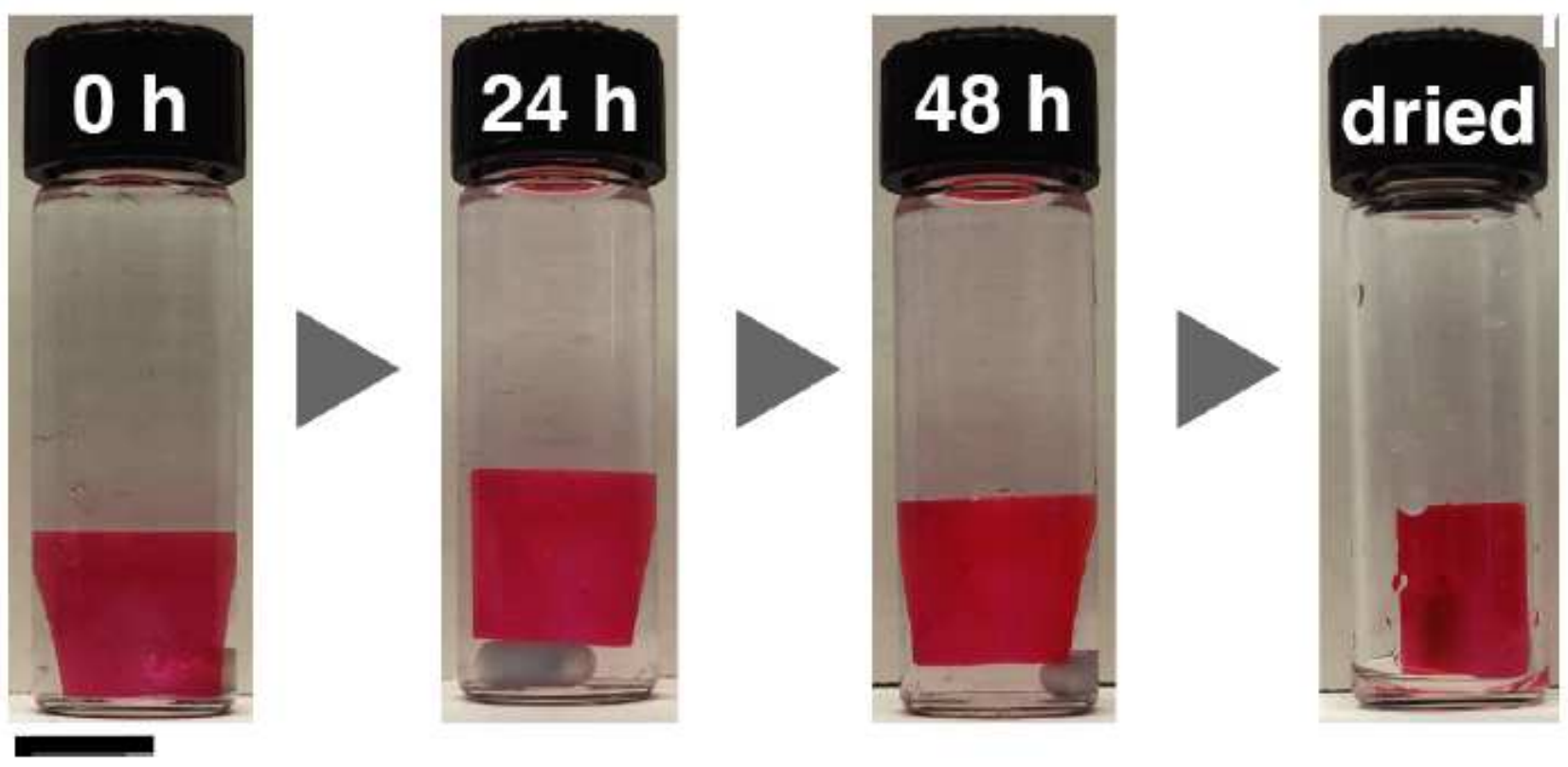

Figure 3

Polyurethane film degradation. a, Dissolution of polyurethane film 10a in $1 \mathrm{M}$ methane sulfonic acid (MSA) in THF followed by removal of solvent. Scale bar, $1 \mathrm{~cm}$. b, Same treatment of polyurethane film 11 leaves the material intact. Scale bar, $1 \mathrm{~cm}$. 
a

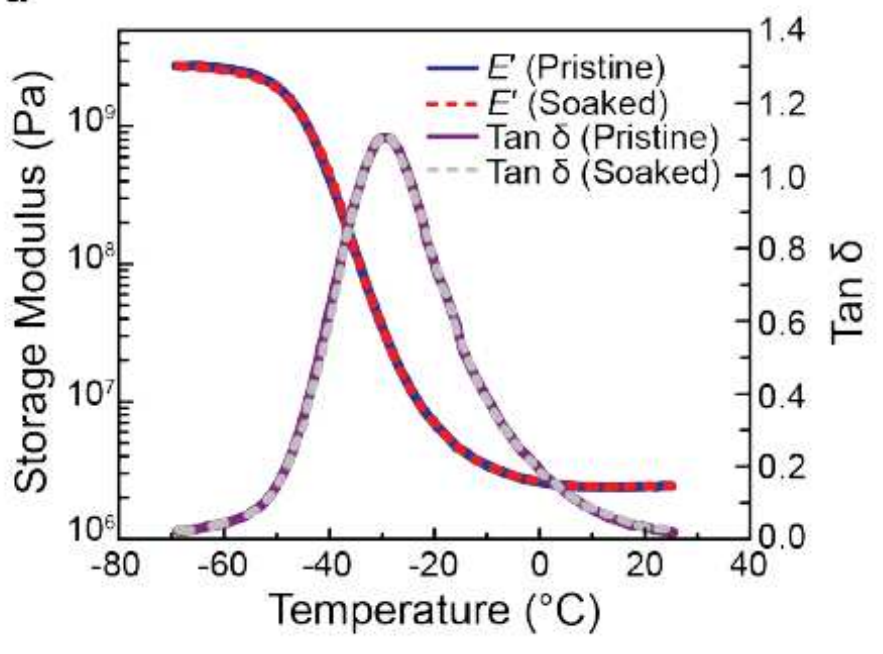

b

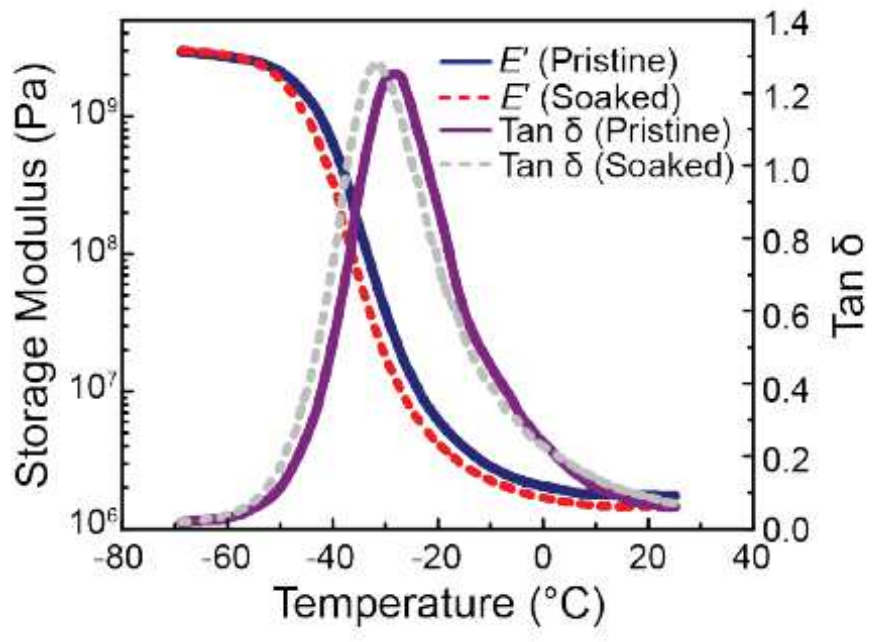

C

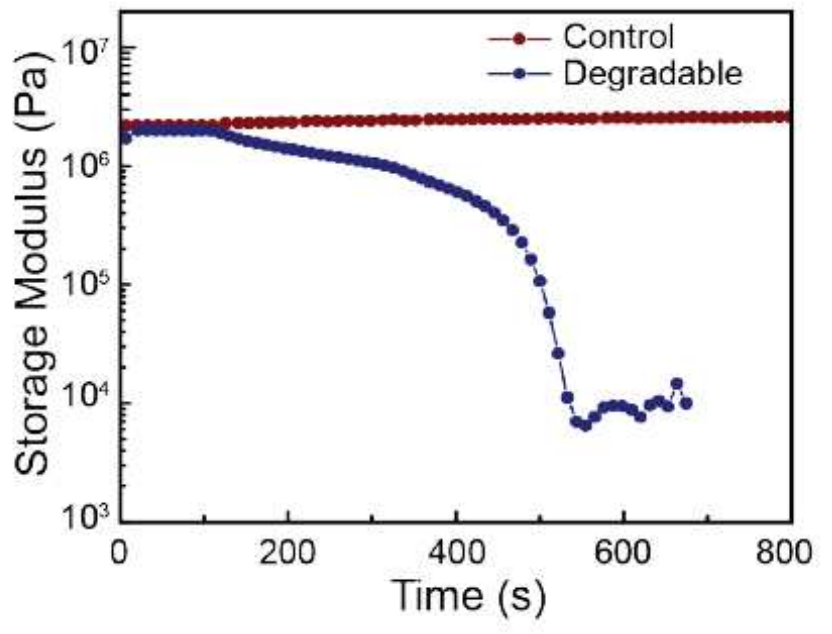

Figure 4

Degradation study of polyurethane elastomer. a, Representative thermomechanical response of 11 films before and after soaking in $1 \mathrm{M} \mathrm{HCl}$ aqueous solution for $24 \mathrm{~h}$ showing $\mathrm{E}^{\prime}$ and $\tan \delta$ from tensile DMA. $\mathrm{b}$, Representative thermomechanical response of 10 a films before and after soaking in $1 \mathrm{M} \mathrm{HCl}$ aqueous solution for $24 \mathrm{~h}$ showing $\mathrm{E}^{\prime}$ and $\tan \delta$ from tensile DMA. c, Storage modulus of $10 \mathrm{a}$ films (blue) and control 11 films (red) immersed in $1 \mathrm{M}$ MSA in THF versus time from tensile DMA. 
a

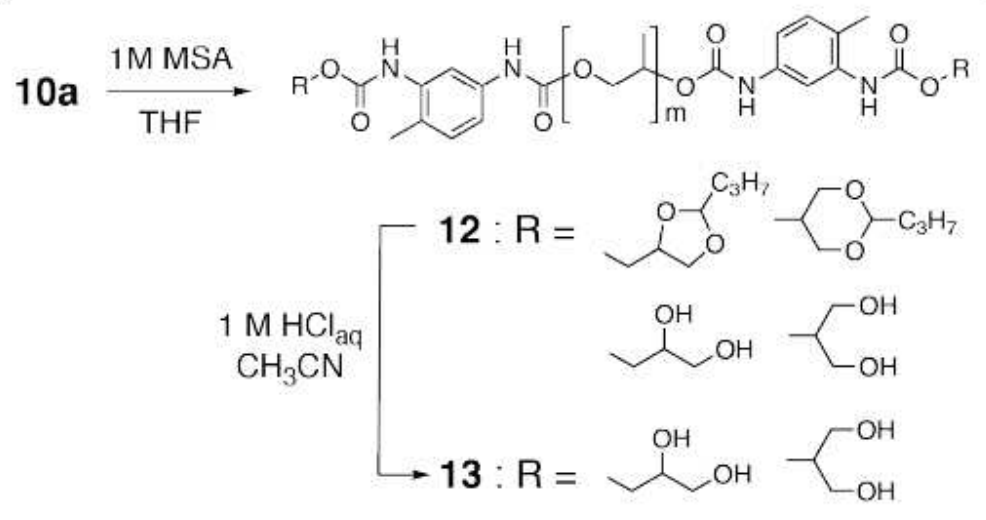

b

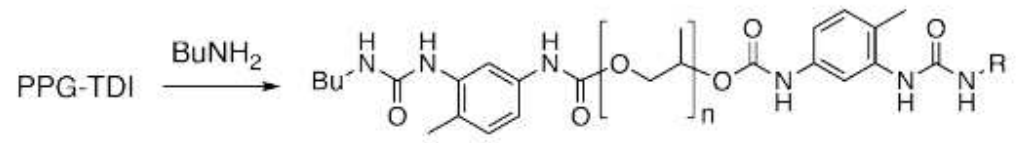

14

d

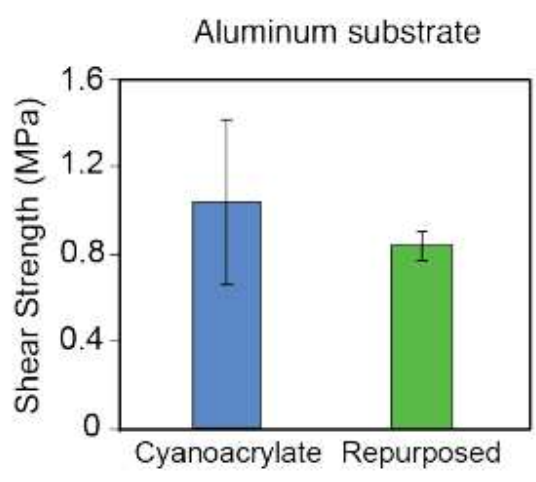

C

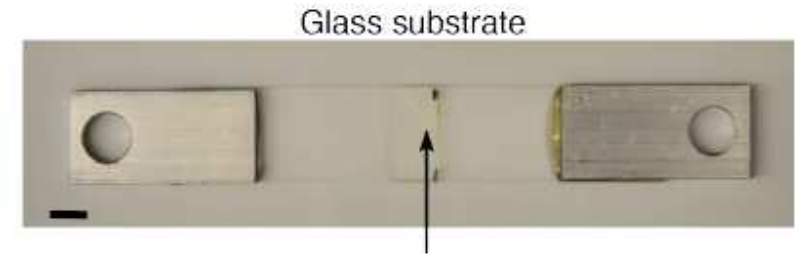

13
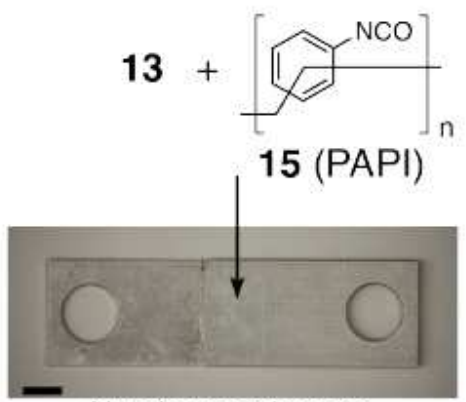

Aluminum substrate
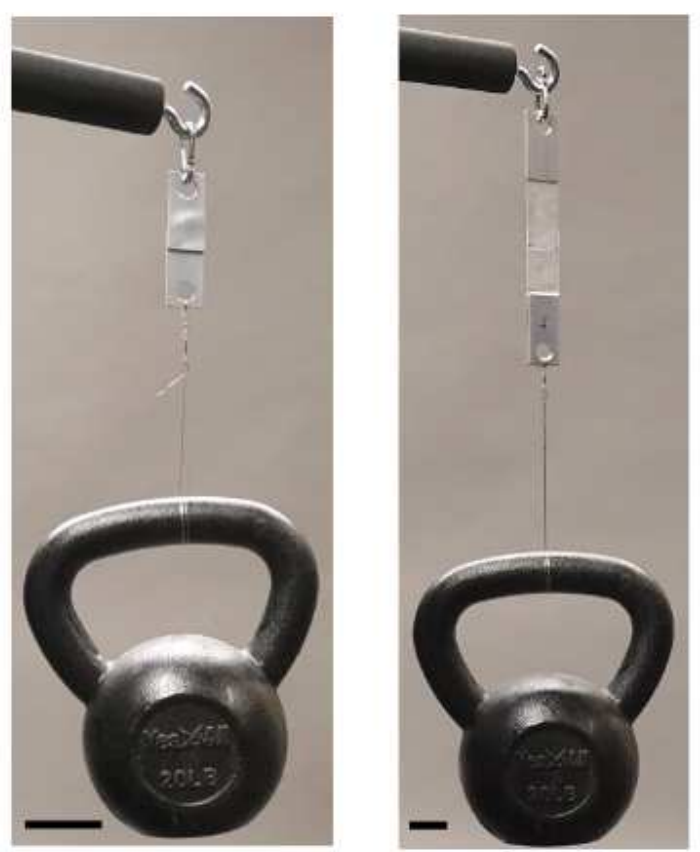

\section{Figure 5}

Repurposing of polyurethane elastomers to strong adhesives. a, Scheme showing possible degradation products from film 10a. b, Preparation of urea 14 as a size standard for MALDI-TOF MS and GPC. c, Fabrication of PAPIbased polyurethane adhesive for steel and glass substrate. Scale bar, $1 \mathrm{~cm}$. A $20 \mathrm{lb}$ kettlebell supported by adhesive on glass substrate and steel substrate. Scale bar, $5 \mathrm{~cm}$. d, Lap shear of repurposed adhesive on steel substrate and comparison with cyanoacrylate. Average of three independent runs with error bars representing standard error of the mean. e, Lap shear results using repurposed adhesive on glass showing shattering the glass with lap-joint intact. Scale bar, $1 \mathrm{~cm}$. 
<smiles>CC(C)n1c(=O)n(CCNC=O)c(=O)n(CCNC(=O)[O-])c1=O</smiles>

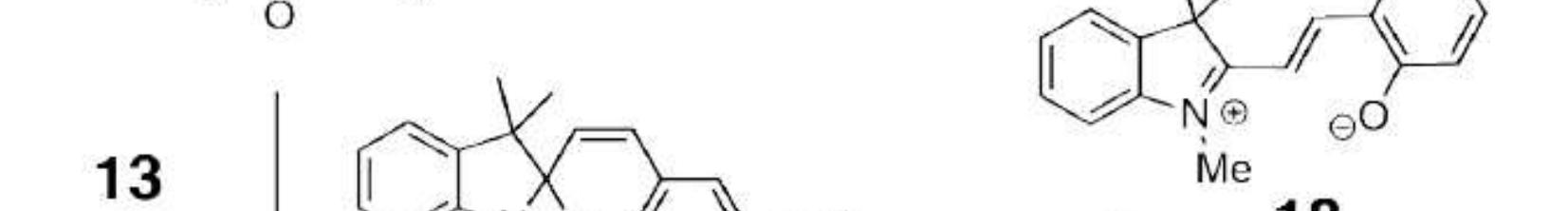

$95^{\circ} \mathrm{C}, 6 \mathrm{~h}$

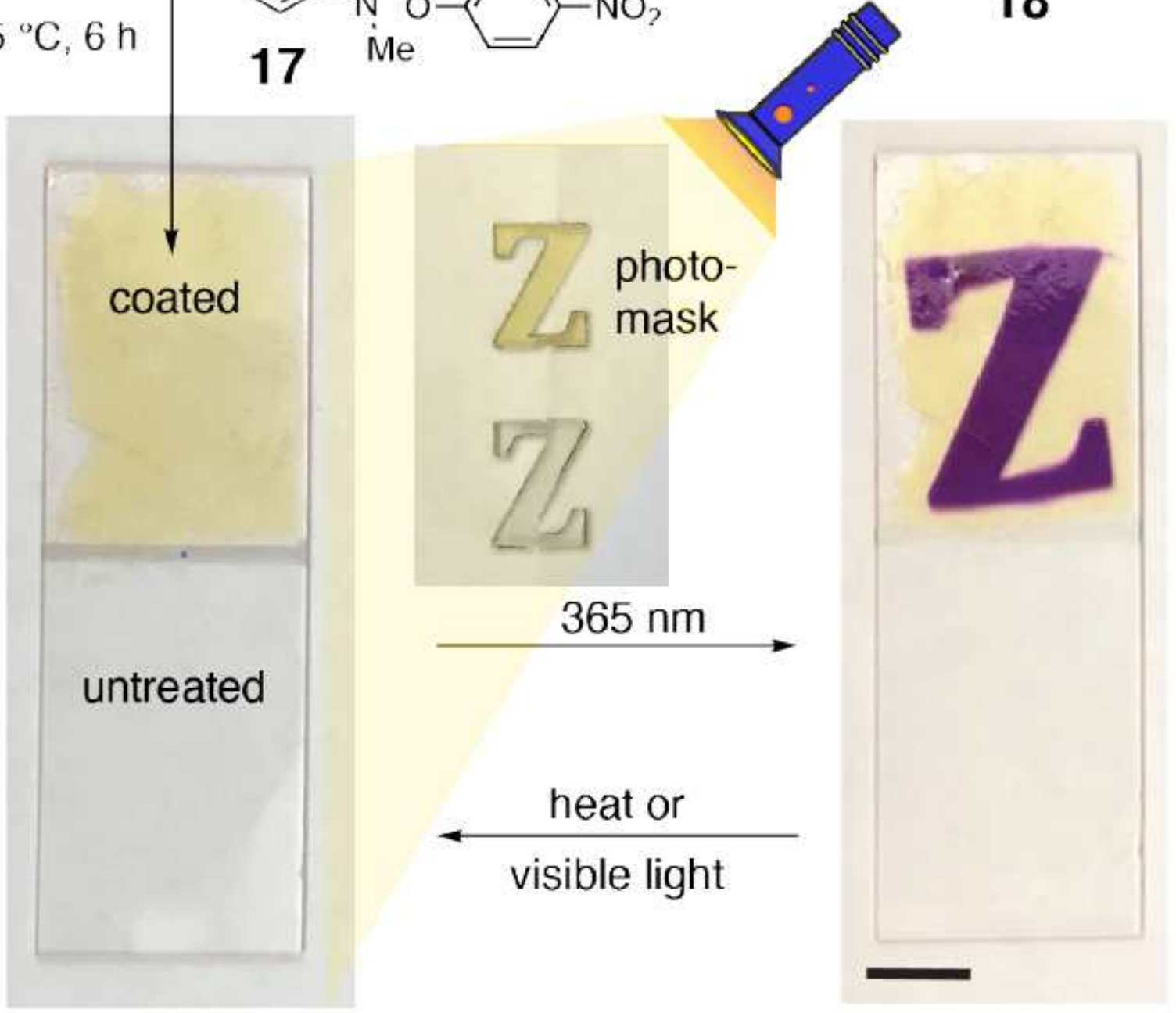

\section{Figure 6}

Repurposing of polyurethane elastomers for photochromic coating. Fabrication of photochromic polyurethane coating on glass slide with coated (top) and untreated (bottom) halves. Photo switchable mechanism of spiropyran dye. c, Photochromic ability of coating demonstrated via 3 min irradiation with $365 \mathrm{~nm}$ longwave hand-held UV light and subsequent exposure to white light (ambient fluorescent laboratory lights) for 30 min reverting back to normal. Scale bar, $1 \mathrm{~cm}$. 


\section{Supplementary Files}

This is a list of supplementary files associated with this preprint. Click to download.

- FilmDegradation.mov

- PhotochromicCoating.mp4

- NatureChemSIEM.NRS.SCZsub1.pdf 